\title{
Proactive interference and the development of working memory
}

\author{
Mollie Hamilton, Ashley Ross, Erik Blaser, \& Zsuzsa Kaldy* \\ University of Massachusetts Boston \\ Developmental and Brain Sciences Program \\ Department of Psychology \\ Boston, MA
}

\section{Accepted at Wiley Interdisciplinary Reviews - Cognitive Science \\ Dec 9, 202 I}

* corresponding author: Dr. Zsuzsa Kaldy, University of Massachusetts Boston, Dept. of Psychology, 100 Morrissey Blvd, Boston, MA, 02 I25, zsuzsa.kaldy@umb.edu

Article type: Focus Article

\section{Author Note}

This project was supported by a grant from the National Institute of Child Health and Development (RI5HD086658). 


\begin{abstract}
Working Memory (WM), the ability to maintain information in service to a task, is characterized by its limited capacity. Several influential models attribute this limitation in a large extent to proactive interference (Anderson \& Neely, 1996; Bunting, 2006; Kane \& Engle, 2000), the phenomenon that previously encoded, now-irrelevant information competes with relevant information (Keppel \& Underwood, 1963). Here, we look back at the adult PI literature, spanning over sixty years, as well as recent results linking the ability to cope with PI to WM capacity (Endress \& Potter, 20I4; Kane \& Engle, 2000). In early development, WM capacity is even more limited (Kaldy \& Leslie, 2005; Simmering, 2012), yet an accounting for the role of PI has been lacking. Our Focus Article aims to address this through an integrative account: since PI resolution is mediated by networks involving the frontal cortex (particularly, the left inferior frontal gyrus) and the posterior parietal cortex (Badre \& Wagner, 2005; Jonides \& Nee, 2006), and since children have protracted development and less recruitment (Crone et al., 2006) of these areas, the increase in the ability to cope with PI (Kail, 2002; De Visscher \& Noel, 2014) is a major factor underlying the increase in WM capacity in early development. Given this, we suggest that future research should focus on mechanistic studies of PI resolution in children. Finally, we note a crucial methodological implication: typical WM paradigms repeat stimuli from trial-to-trial, facilitating, inadvertently, $\mathrm{PI}$ and reducing performance; we may be fundamentally underestimating children's WM capacity.
\end{abstract}

Keywords: working memory, interference, development, capacity, cognitive control 


\section{Introduction}

Proactive interference $(\mathrm{PI})$ occurs when there is a failure to inhibit previously learned, currently irrelevant information, resulting in memory retrieval difficulties (errors or slower responses). PI can stem from old memories, like putting last year's date on a document weeks after New Year's, or recent ones, like that moment of doubt when adding that fourth (or did I already add four?) scoop of sugar to the cake batter. In either case, now-irrelevant information has intruded into working memory (WM), the limited capacity system in which information is temporarily activated and manipulated in order to complete a task (Baddeley \& Hitch, 1974). This means that while the source of the irrelevant information may vary, the competition between 'retrieval candidates' plays out in WM (and makes the distinction between paradigms that target longer-term visual memory versus working memory per se less crucial for understanding the effects of $\mathrm{PI}$ in WM).

PI has been studied extensively in adults since the 1960's (Keppel \& Underwood (1962); for an excellent recent overview, see Kliegl \& Bauml (202I)). Results from a number of WM studies have been re-analyzed to quantify the effects of $\mathrm{PI}$ in school-age children, but there is still a major gap in the literature concerning $\mathrm{PI}$ in young children, particularly under the age of 4 . In this paper, we will examine five threads in the literature: I) PI is a primary factor limiting WM in adults (Endress \& Potter, 2014; Oberauer et al., 2016), 2) The ability to resolve $\mathrm{PI}$ is mediated by a network involving the fronto-parietal system and the medial temporal lobe (Badre \& Wagner, 2005; Jonides \& Nee, 2006; Öztekin et al., 2009), 3) WM is more limited in children than in adults (Kaldy \& Leslie, 2003, 2005; Kibbe \& Leslie, 2013; Ross-Sheehy et al., 2003; Simmering, 2012), 4) Children are sensitive to the effects of PI (Kail, 2002), and 5) the network underlying PI resolution is immature in children (Polspoel et al., 2019). Tying these threads together, we argue that developmental increases in the ability to cope with PI is a primary driver of developmental increases in WM capacity.

\section{Interference limits working memory capacity}

Two main theories have been put forth to explain WM capacity limitations: interference (discussed further below) and decay (Towse \& Hitch, 1995). One of the stronger arguments for the role of decay in WM comes from the Time-Based Resource Sharing model (TBRS) of Barrouillet and Camos (2004). Here, to offset decay, one must constantly refresh to-be-remembered information during any delay prior to recall. Thus, according to this model, the longer one needs to maintain information, the more successful one would be at recall because of the additional opportunities to refresh. Barouillet and Camos provided evidence for this model by filling this delay period with additional tasks of varying lengths, finding that recall performance decreased as these additional tasks occupied more of the delay (Barrouillet et al., 2004, 2007). However, here it is difficult to distinguish the reduction in recall performance due to the shorter unadulterated delay times from the additional demands, in terms of attention and capacity load, that the added tasks placed on WM. A recent review concluded that decay plays a fairly marginal role in keeping information in WM, and instead identified interference as the major limitation (Oberauer et al., 2016).

The interference theory postulates that what causes us to be more or less likely to keep (task-relevant) items active in WM is our ability to cope with interference from other sources. These sources can be (I) previously encoded memories (that is, PI), (2) salient perceptual information in the environment (distraction), or (3) interference between multiple items needed to be kept in WM (similarity-based competition). Computational models developed to test competing models of limited WM capacity have reached similar conclusions (Brown et al., 2007; Oberauer et al., 2012). Oberauer and his collaborators (20I2) developed a computational model called the "serial-order-in-a-box complex-span" (SOB-CS), which posits interference as a main cause of forgetting rather than temporal decay. They found that SOB-CS outperformed the decay-based TBRS model in predicting behavioral data, suggesting that forgetting from WM can be better understood through interference. Similarly, Brown et al. (2007) found that a model that assumes that all types of forgetting are due to interference rather than decay predicted the findings of classic PI experiments (Underwood, 1957) very well. Thus, there is substantial evidence from both behavioral and computational studies that interference is a major constraint on WM in adults, and as we argue below, must be considered in the developmental trajectory of WM capacity.

Many studies have demonstrated that PI (as opposed to other forms of interference) is one of the main limitations on WM capacity (Anderson \& Neely, 1996; Bunting, 2006; Endress \& Potter, 20I4; Kane \& Engle, 2000; Lustig et al., 200I). These effects in memory were first demonstrated with tasks using verbal stimuli (Keppel \& Underwood, 1962; Wickens et al., 1963). Here, participants were given a list (a series of numbers, letters, or syllables), then asked to count backwards during a brief retention period, and then finally asked to recall the list. 
Participants' ability to recall the lists decreased as trials went on. Importantly, this was not due simply to fatigue, as participants could be "released" from the effects of PI by changing the type of the stimuli (e.g., from numbers to letters) (Wickens et al., 1963).

Further supporting the role of PI is Kane \& Engle's (2000) seminal study comparing individuals with lowversus high-WM capacity. Here, participants performed a WM task in parallel with a secondary task that varied in terms of attentional load. The 'high load' condition required participants to tap their fingers on the table in a complex novel sequence, whereas the 'no load' condition was a repetitive pattern that minimized attentional demands. The WM task was to recall lists of words, and the design was the classic buildup-and-release-from-PI following Wickens et al. (1963). The words appeared one at a time on a screen and the participants were to read the words as they appeared. After a retention task, the participant was to recall the words orally. The first three lists were words drawn from the same semantic category (i.e. animals), and the fourth list was from a novel category (i.e. names of countries). As expected, a buildup of PI was seen across the three lists from the same category (fewer number of correctly recalled words in each subsequent list), and a release from PI was observed with the fourth list from the novel semantic category. Importantly, in the 'no load' condition, low-WM capacity individuals were more susceptible to PI than high-WM capacity individuals, while in the high-load condition there was no difference in PI susceptibility. In other words, the low-WM capacity group's susceptibility to PI did not change as a function of attentional load but the high-WM capacity group's did (see Figure I). This suggests that, in the low-load condition, high-WM capacity individuals had available attentional resources they could employ to help resolve PI, whereas low-span individuals did not. When attention was occupied in the high-load condition, high-WM capacity individuals no longer had available attentional resources, and therefore their results mirrored the results of the low-WM capacity individuals. This study, along with similar results from other paradigms (Bunting, 2006; Lustig et al., 200I) provides strong evidence that WM capacity is highly dependent upon one's ability to cope with PI.
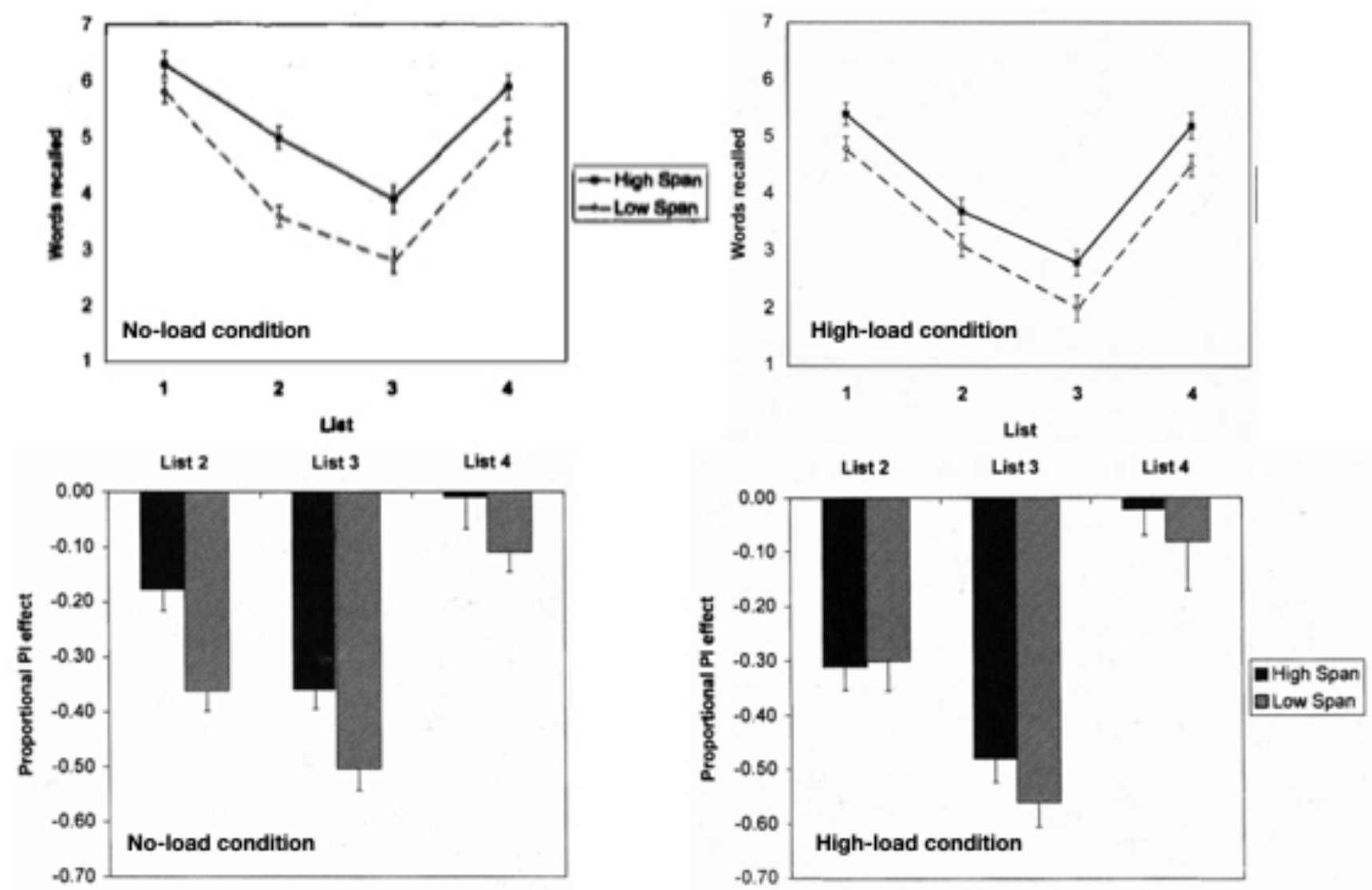

Figure I. The results of Kane \& Engle (2000) show the difference in words recalled across lists in the no-load condition and high-load conditions among high-span vs. low-span individuals. The bar graphs show the PI effect in the two groups of individuals demonstrating that the low-span individuals' ability to cope with PI does not differ significantly when attentional load is increased. 
While most of the research on $\mathrm{PI}$ over the past 60 years has used verbal stimuli, recent studies have shown that PI occurs in visual working memory as well (Endress \& Potter, 20I4; Hartshorne, 2008; Makovski \& jiang, 2008). (We turn our focus to visual WM because this is how WM is measured in early development since testing preverbal infants and young toddlers with lists of words is not possible.) For example, Makovski and jiang (2008) presented participants with a classic change detection paradigm where an array of different colored disks was presented and after a retention interval, they were presented with another display containing one colored disk (probe). Participants were to determine if the probe was in the same location and was the same color as what they had seen on the previous array. Participants were most likely to make an error when the probe matched the color and location of an array from the previous trial; strong evidence of PI. In addition to this, Hartshorne (2008) demonstrated that in the same classic change detection paradigm, PI effects from a single item can persist for up to 3-4 trials. Endress and Potter (2014) presented a more striking demonstration of the power of interference to modulate effective WM capacity. In this study, participants were presented with a set of pictures presented serially at the same location, followed by a probe item. The task was to identify if the probe was novel, or a member of the previously presented set of pictures. Here, they showed that in a condition designed to avoid PI (pictures were never repeated), estimated memory capacity did not appear to be fixed, but instead increased as a function of set size, and far exceeded the classic 3-4 item limit (Cowan, 200I), reaching estimates as high as 30 items (see Figure 2). When instead PI was present (pictures were repeated, selected from the same superset, with replacement), capacity was limited to 3-4 items, largely independent of set size. (This pattern of results was so inconsistent with the conventional understanding of WM that Endress and Potter (2014) avoided direct attribution to WM, per se, and instead implicated temporary visual memory: when interference is minimized, temporary visual memory has no definite capacity, while in the presence of PI, it has the strict limitations typically associated with WM.)
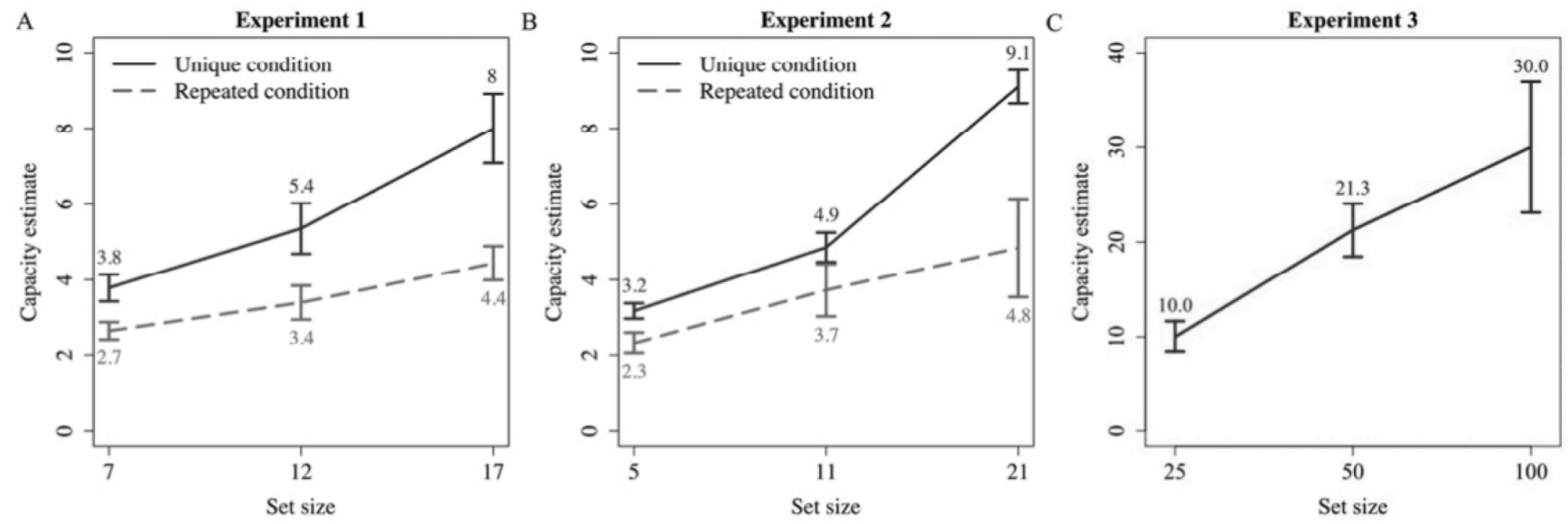

Figure 2. Results of Endress and Potter (20I4) showing large visual WM capacity estimates in conditions with unique relative to repeated stimuli. Strikingly, participants were able to correctly remember 30 out of 100 unique items (Experiment 3).

The size of the PI effect in visual WM remains an area of debate. For example, both Hartshorne (2008) and Makovski \& Jiang (2008) found evidence of PI in visual WM using a classic change detection task. In this task, participants are presented with an array of objects on a screen, then after a brief retention period they are shown a probe and they have to report whether the object belonged to the initial array or not. However, in these studies, the effect of PI only decreased performance by about 15\%. Lin and Luck (20I2) argued that the effects of PI can actually be eliminated completely in the change detection task and have therefore questioned its importance in visual WM altogether. A follow-up study conducted by Makovski (2016), however, provided an explanation for the discrepancy between the findings of Endress and Potter (2014) and the studies that used change detection. He showed that spatial location is a critical factor in determining the effects of PI in visual WM. Makovski (2016) showed that the effects of PI are in fact substantial in visual WM, but that they are specific to each item's spatial location. 
As well, beyond spatial location, the magnitude of the PI effect can depend on several other factors, such as the similarity of items, the length of the retention time, and whether participants are allowed to use verbal rehearsal (Cyr et al., 2017; Endress \& Potter, 2014; Loess, 1967; Wickens et al., 1963). Additionally, temporal distinctiveness can also affect a participant's sensitivity to $\mathrm{PI}$, that is, the longer the interval between trials, the less PI will affect performance (Kincaid \& Wickens, 1970; Shipstead \& Engle, 2013). Taken together, while there is a lot to be learned about the impact of PI, it is clear that it is a significant factor limiting the effective capacity of visual WM and, as such, needs to be accounted for when modeling the increasing capacity of visual WM over development.

\section{The resolution of $P I$ is mediated by a network of fronto-parietal areas and the MTL}

An influential mechanistic explanation of memory retrieval was put forth by Michael Anderson and his colleagues (for reviews, see (Anderson, 2003; Anderson \& Hulbert, 2021; Anderson \& Neely, 1996; Levy \& Anderson, 2002). The starting point of this model is that retrieval always involves a decision between candidates that have been activated based on retrieval cues. The winner is not simply the candidate that gets the highest activation, but according to Anderson and his colleagues, competing candidates need to be actively inhibited. Empirical support came from studies such as Anderson and Green (200I), which showed that actively inhibiting a previously learned association leads to later retrieval errors (with attention likely required to accomplish this active inhibition (Anderson et al., 2004; MacDonald et al., 2000)). Anderson and colleagues (2004) showed that the same neural mechanism that inhibits competing motor responses (i.e. in Go/No-Go tasks) is used during memory retrieval to inhibit the competing candidates. As well, brain areas such as the anterior cingulate cortex (ACC) and the dorsolateral prefrontal cortex (dIPFC) are active during both motor tasks that require response override as well as during memory retrieval, especially in the presence of interference. Beyond the ACC and the dIPFC, the resolution of $\mathrm{PI}$ involves a complex network of brain areas including areas in the prefrontal cortex (PFC), posterior parietal cortex (PPC), and in the medial temporal lobe (MTL) (see Figure 3). Here we will review what is known about these networks, in adults, and then in Section 6 turn to the developmental work to overview the relative maturation of these areas in children.

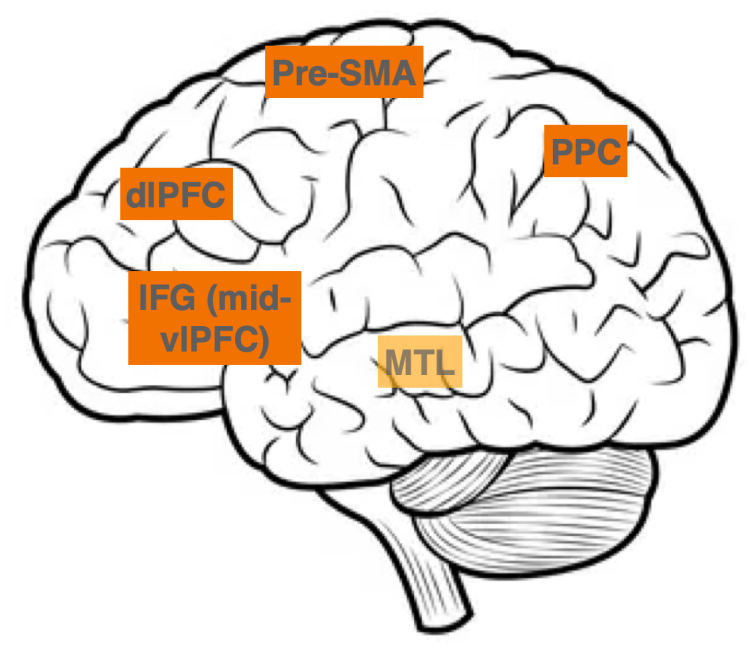

Figure 3. Brain areas involved in PI resolution: IFG (inferior frontal gyrus, or mid-ventrolateral prefrontal cortex, vIPFC), pre-SMA (pre-supplementary motor area), dIPFC (dorsolateral prefrontal cortex), PPC (posterior parietal cortex), areas in the MTL (medial-temporal lobe). MTL is in lighter color to indicate its medial position (not visible in this lateral view).

The first study that identified brain areas underlying PI resolution was done by John Jonides and his colleagues using PET (Jonides et al., 1998) in a recent probes task. The recent probes task is a classic paradigm (Monsell, 1978) where participants are presented with a set of to-be-remembered items and then asked to do a filler task. They are then presented with a probe item and asked to determine whether it belonged to the previous set or not. Crucially, on recent negative trials, the item did not belong to the set of items presented in the current trial, but was in the previous trial. They found that participants were slower and less accurate on these recent negative probes than when tested with items that were novel (not shown in the previous trial). The left IFG 
(inferior frontal gyrus) of the lateral PFC was more active when interference was high (i.e. in the recent negative trials). (Besides the recent probes task, other classic paradigms have also been used in recent imaging studies of $\mathrm{PI}$, such as directed forgetting (Bjork et al., 1968). In the directed forgetting task, participants are presented with information to memorize, but then asked to forget a subset of that information. Participants are then presented with a probe and asked to identify whether that probe belonged to the to-be-remembered set or not. PI occurs when the information that was to be forgotten is activated during retrieval. Nee and his colleagues found that the same network was activated in both their recent probes and directed forgetting tasks (Nee et al., 2007).)

In addition to the IFG, other regions contributing to the network have been identified, in the frontal cortex, most notably, the dorsolateral prefrontal cortex (dIPFC) and the pre-supplementary motor area (preSMA), as well as areas outside of the frontal cortex, such as the posterior parietal cortex (Badre \& Wagner, 2005; Bunge et al., 200I; Feredoes et al., 2006; Jonides \& Nee, 2006; Mecklinger et al., 2003). Not surprisingly, given the central role of interference resolution in WM, these are also the same areas that have been consistently implicated in WM tasks in general (Curtis \& D'Esposito, 2003; Duncan \& Owen, 2000). Using a recent probes task, Öztekin, Curtis and McElree (Öztekin et al., 2009) found differential activation to interference in both the IFG and areas in the MTL. Crucially, they found activity in the IFG in the presence of PI, regardless of whether the subject was successful on the task. In contrast, activity in the MTL appeared to be correlated with correct responses, suggesting that the MTL is crucial for being successful at the resolution of PI. The involvement of the MTL (in particular, the parahippocampal cortex) was confirmed in a subsequent fMRI study using MVPA (multivoxel pattern analysis) (Öztekin \& Badre, 20I I). A developmental lesion study in primates showed further converging evidence regarding structures in the MTL and the connections between the MTL and the PFC in the resolution of PI. Weiss and colleagues (Weiss et al., 2015) showed that neonatal lesions to the perirhinal cortex in adult monkeys resulted in an ability to inhibit the effects of PI. That is, in tasks that used repeated stimuli and therefore had high PI, the animals were more likely to commit errors than when tested with trial-unique stimuli. This data confirms that areas in the MTL (parahippocampal and/or perirhinal cortex) are also important nodes in the network involved in the resolution of $\mathrm{PI}$.

A review by Irlbacher, Kraft, Kehrer and Brandt (20I4) asked the question of whether the involvement of the different areas of the PI resolution network, as well as their timing, may differ depending on the type of control processes used to resolve interference $A$ highly influential general framework of cognitive control distinguishes two types of control processes: proactive versus reactive control (Braver, 2012; Braver et al., 2007). For example, in the recent probes task, the participant can only begin to address the effects of PI once the negative probe has been introduced (reactive control). If, however, after participants have been exposed to several recent negative probe trials, they might begin to anticipate and try to prepare for the interference before the onset of the negative probe (proactive control). In their review, Irlbacher and colleagues find some evidence for the differential activation patterns (proactive versus reactive) within the network of areas outlined above, in time, but with a substantial overlap. From our developmental perspective, it is important to note that the current view is that young children are only able to engage in reactive control, with proactive control only emerging in mid-childhood (Chatham et al., 2009; Chevalier et al., 20I5).

\section{Working memory is more limited in children}

Infants' working memory is more limited than adults', and capacity steadily increases across development (Kaldy \& Leslie, 2003, 2005; Kibbe \& Leslie, 20 I3; Pelphrey et al., 2004; Ross-Sheehy et al., 2003; Simmering, 20I2). (Infant studies have focused on visual WM, since using verbal stimuli is not possible.) Beyond infancy, WM capacity continues to grow, reaching adult levels by late childhood (Cowan et al., 2005; Gathercole et al., 2004; Riggs et al., 2006). In a highly influential review, following the roadmap laid out by Dempster (I98I), Cowan aimed to identify the factors underlying WM development in both younger and older children (Cowan, 2016). Besides the growth of pure 'scope' (capacity) of WM, high-level mnemonic strategies such as chunking and verbal rehearsal also affect WM capacity estimates. But young children (under 5 years of age) are less adept at spontaneously using such strategies (see Elliott et al., 202I), and this may make them more susceptible to the effects of PI.

Beyond these differences in strategy use, Cowan (2016) also pointed out the difficulties connecting performance measures in infants versus children that stem from the inevitable differences in task demands and how performance is quantified in different tasks. After surveying the literature on children under 6 years of age, he concluded that more research is needed on the influence of cognitive control, and whether the scope of WM develops independently from these mechanisms. The goal of this review then, is in line with Cowan's suggestion, 
as we argue that the development of cognitive control mechanisms underlying PI resolution is a significant factor driving increases in WM capacity.

\section{PI affects memory in children}

Following the discovery of $\mathrm{PI}$ as a crucial aspect of memory in studies with adults (Wickens et al., 1963; Wickens, 1970), developmental researchers became interested in studying its effects in young children. Most of these early studies involved school-age participants, with the exception of three studies that studied preschoolage (4-5-year-old) children (Rosner, 1972; Esrov et al., 1974; Reutener \& Fang, 1985). However, instead of quantifying the effect of $\mathrm{PI}$ on WM itself, the main goal of these studies was to use the PI buildup-and-release paradigm as a tool to study categorization and concept formation in children. These early studies in the 70's and 80 's were followed by others designed to measure Pl's effects on school-age children's memory. We have summarized all previous studies of PI effects in children in Table I. Across all I5 studies, it is clear that PI is a robust phenomenon throughout development, and that the effect is stronger in younger children (one exception is Chiappe et al. (2000), which we discuss below.)

To date, the strongest evidence for the claim that PI is not simply present but is higher in younger children comes from a meta-analysis by Kail (2002). He reanalyzed a large set of previous studies (26 studies, 86 datasets) that used a Brown-Peterson task to study working memory in 4-14-year-old children. The Brown-Peterson task is a classic paradigm used to measure memory capacity. Here, lists of words are given to the participants and, after a brief retention period where verbal rehearsal is blocked (usually by counting backwards), the participants are asked to recall words from the list. Since these were not PI studies per se, Kail analyzed whether there was a decrease in performance across the first three trials, as would be expected as the detrimental effects of PI accumulate. The meta-analysis revealed that the effect of PI was considerable, more so in younger than in older children, but the ability to cope with PI increased steadily with age. In a second, empirical study, Kail tested 9-I3year-old children and college students in a Brown-Peterson task, with 4 consecutive trials (Kail, 2002). Here, he found a similar pattern to what was shown in the meta-analysis: performance decreased across trials and younger children were more susceptible to PI than older children and adults (see Figure 4).

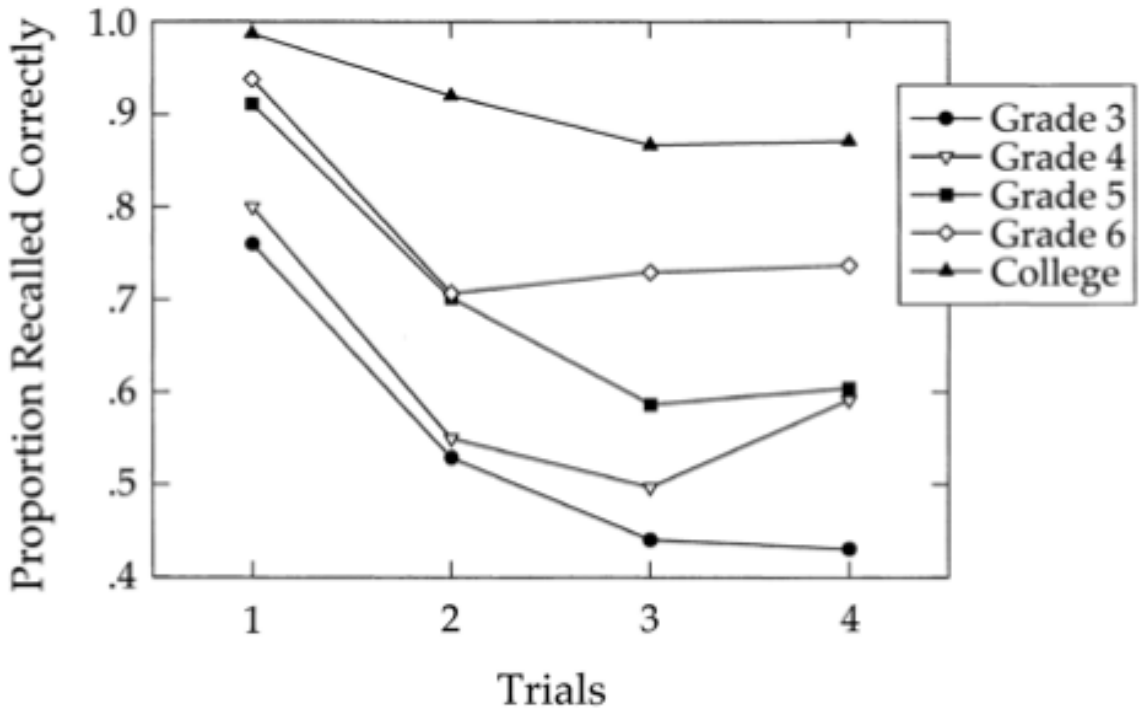

Figure 4. Results of Kail (2002). 9- to I2-year-old children and young adults were tested in four trials of a BrownPeterson task. The effect of proactive interference decreased with age.

This same developmental trend was confirmed by Carriedo and collaborators (Carriedo et al., 2016). There, participants performed a guided recall of items from word lists. They found that the proportion of errors due to intrusions from previous lists (i.e., errors due to $\mathrm{Pl}$ ) decreased from 7 to 15 years, at which age the ability to inhibit the previous list intrusions appeared adult-like. In the visual domain, Loosli and colleagues (Loosli et al., 2014) found similar results using a recent probes task in 8-I4-year-olds. In this task, children were presented with 


\begin{tabular}{|c|c|c|c|c|c|}
\hline Authors & year & age (range) & paradigm & $\begin{array}{l}\text { modality of } \\
\text { stimuli }\end{array}$ & Results \\
\hline Tyrrell et al. & 1990 & 20-30 weeks & $\begin{array}{l}\text { paired comparison test of preference } \\
\text { for novelty }\end{array}$ & visual & $\begin{array}{l}\text { Infants were familiarized with upright photographs, rotated photographs, or rotated caricatures } \\
\text { and all infants were tested with upright photographs (novel vs. familiar). Only infants in the } \\
\text { caricature group had a novelty preference (which is evidence of a release from PI). }\end{array}$ \\
\hline Esrov et al. & 1974 & $3-4$ years & STM task (/w release from $\mathrm{PI})$ & visual/auditory & A buildup of $\mathrm{PI}$ and a release from $\mathrm{PI}$ was observed. \\
\hline Reutener \& Fang & 1985 & $3-5$ years & Brown-Peterson & visual & A buildup of $\mathrm{PI}$ and a release from $\mathrm{PI}$ was observed. \\
\hline Rosner & 1972 & $4-5$ years & Brown-Peterson $(\mathrm{w} /$ release from $\mathrm{Pl})$ & visual & $\begin{array}{l}\text { Testing with repeated items produced a buildup of PI whereas testing with novel items did not. } \\
\text { Location shift did not result in a release from } \mathrm{PI} \text {, but a presentation of novel items did. }\end{array}$ \\
\hline Aydmune et al. & 2020 & $6-8$ years & Brown-Peterson ( $w /$ release from $\mathrm{Pl})$ & visual/auditory & The ability to cope with PI and fluid intelligence did not signficantly correlate. \\
\hline Chiappe et al. & 2000 & 6-9/10-19/adults & listening span task & auditory & $\begin{array}{l}\text { All age groups were effected by } \mathrm{PI} \text {, but there were no significant differences between the age } \\
\text { groups or among poor readers and typical readers. }\end{array}$ \\
\hline Cann et al. & 1973 & $7-8$ years & Brown-Peterson $(\mathrm{w} /$ release from $\mathrm{PI})$ & auditory & A buildup of $\mathrm{PI}$ and a release from PI was observed. \\
\hline Tyrrell et al. & 1981 & $7-11$ years & Brown-Peterson ( $w /$ release from $\mathrm{Pl})$ & visual/auditory & $\begin{array}{l}\text { Build-up of } \mathrm{PI} \text { occurred in all ages and in both modalities. A release from } \mathrm{Pl} \text { in both age groups } \\
\text { was only observed if the stimuli was changed from auditory to visual but not from visual to } \\
\text { auditory. }\end{array}$ \\
\hline Bjorklund et al. & 1982 & 8 years & Brown-Peterson $(\mathrm{w} /$ release from $\mathrm{PI})$ & visual & $\begin{array}{l}\text { A buildup of PI both when items were typical of the category or when they were atypical. Release } \\
\text { from PI was only observed when the items were typical. }\end{array}$ \\
\hline Halford et al. & 1988 & $\begin{array}{l}8-9 \text { years } / 15 \\
\text { years/adults }\end{array}$ & item recognition task & visual & In all age groups the effects of PI increased with set size. \\
\hline Loosli et al. & 2014 & $\begin{array}{l}8-10 \text { years/11-14 } \\
\text { years/adults }\end{array}$ & Recent probes and N-back & visual & $\begin{array}{l}\text { In the recent probes task children commited more } \mathrm{PI} \text { related errors than young adults, but in the } \\
\mathrm{N} \text {-back task younger children commited less } \mathrm{PI} \text { related errors than young adults. }\end{array}$ \\
\hline Bayliss \& Jarrold & 2015 & 9 years & $\begin{array}{l}\text { forgetting tasks/WM span } \\
\text { tasks/storage } \\
\text { tasks/processing-efficiancy tasks }\end{array}$ & visual/auditory & $\begin{array}{l}\text { Children's working memory span performance can be explained by three separable factors: } \\
\text { storage ability, general speed of processing, and the rate at which one forgets information. }\end{array}$ \\
\hline Leslie & 1975 & $9-11$ years & $\begin{array}{l}\text { serial-order STM task }(\mathrm{w} / \text { release } \\
\text { from } \mathrm{PI})\end{array}$ & visual & $\begin{array}{l}\text { Typically developing children and children who had a developmental delay in reading were } \\
\text { compared. Both groups showed buildup and release of PI. Overall performance in children with a } \\
\text { reading delay was lower. }\end{array}$ \\
\hline Kail & 2002 & $9-12$ years/adults & Brown-Peterson & auditory & The ability to cope with PI increases with age. Overall performance is correlated with age. \\
\hline Borella et al. & 2010 & $10-11$ years & $\begin{array}{l}\text { numerical updating and } \\
\text { Brown-Peterson }\end{array}$ & visual & $\begin{array}{l}\text { Poor reading comprehenders are less accurate in WM tasks and more susceptible to PI than } \\
\text { good reading comprehenders. }\end{array}$ \\
\hline
\end{tabular}

Table I. Studies that investigated the effect of proactive interference (PI) on children's WM performance. The list is ordered by the age of the youngest participants. PI - proactive interference, STM - short term memory, Brown-Peterson - Brown-Peterson task (see text for details.)

a target set that consisted of four pictures of nameable animals, followed by a brief retention period. Then they were presented with a probe picture and asked to report whether it matched an animal from the target set. On some trials, the probe item was not in the target set, but had been in the target set of the previous trial, setting up an opportunity for PI. Children (8-10 and II-|4-year-olds) committed more PI-related errors than young adults. In the same study, they also conducted a N-back task with repeated items. Here, children were shown a sequence of pictures of animals. With each subsequent picture, the children were to determine whether the animal was the same as that presented two pictures prior. In a critical lure condition, the target picture did not match the one two images prior, but instead the one three images prior, thereby provoking PI. Surprisingly, the younger child group made fewer Pl-related errors than young adults. The authors suggest that the n-back task is particularly challenging, and indeed the data showed that the younger children had more difficulty remembering the items two positions back. In order to see the effects of $\mathrm{PI}$, they argued, one not only has to remember the item two positions back but also three positions back once the lure is introduced. (This may be a factor as well in the study of Chiappe et al. (2000), mentioned above. There, the youngest age group (6-9 years old) did not have more overall intrusion errors than older children or adults, as one might expect. But they did have by far the lowest overall memory for word list items. Following the explanation of Loosli et al. (2014), the 6-9-year-olds may have had fewer intrusion errors simply because they had fewer remembered items to intrude.)

But what is the mechanism that underlies the development of PI resolution? Recall the model of memory retrieval by Anderson and colleagues discussed in Section 3 above (Anderson, 2003; Anderson \& Hulbert, 202I; Anderson \& Neely, 1996; Levy \& Anderson, 2002), where retrieval involves a decision between candidates that have been activated based on recall cues, where competing candidates need to be actively inhibited. With this model in mind, we can hypothesize two potential processes. (I) There could be a reduction in cue 'overlap' across development (the tendency to activate multiple memories by a single cue). This could happen through more precise memory encoding processes with age (Burnett Heyes et al., 2012; Guillory et al., 2018). On the other hand, the growth of children's knowledge base means that the same cue will be associated with more potential retrieval candidates. (2) Children get better at exerting the inhibitory control that is needed for candidate 
inhibition. This is a more likely explanation, as the immaturity of inhibitory control in children have been welldocumented in multiple domains (Davidson et al., 2006; Durston et al., 200I; Wolfe \& Bell, 2004). Clearly, this is an important question for future research.

PI effects in children have also been demonstrated outside of the laboratory, such as in math education. The learning of a series of math facts with shared numerals, for instance multiplication problems, is a situation where interference strongly affects learning (De Visscher \& Noël, 20I4). For example, learning the problem $9 \times 3$ $=27$ is harder than learning $5 \times 5=25$ because there are more multiplication problems that contain the numerals $\{9,3,2,7\}$ relative to $\{5,2\}$. To capture this, De Visscher \& Noel (2014) assigned an interference parameter to multiplication problems according to the number of numerals shared with other problems. They also weighted them according to the order in which they are typically taught to children (from ' 2 times' multiplication tables to ' 9 times' tables). They found that the interference parameter could predict performance on multiplication problems on previously published reaction time data from young adults (Campbell, 1997). They also found that the level of interference was positively correlated with reaction time in a speeded task in both 8- and 10-yearolds and in a new study with young adults. They further argued that the interference effect might be one of the mechanisms behind dyscalculia, a learning disability where individuals struggle with the learning of math facts (De Visscher et al., 2015).

Despite the importance of $\mathrm{PI}$ in memory and the evidence demonstrating the effect of PI in older children, very few studies to our knowledge have explicitly looked at the effects of PI in children younger than 4 years of age. One study in 5-7-month-olds exploited the effects of PI to demonstrate that infants were able to form categories of faces (Tyrrell et al., 1990). Here, when infants were familiarized with a set of face stimuli that were highly similar to the test stimuli (e.g, right-side up photographs) they were less likely to show a novelty preference than infants who were familiarized with stimuli that differed greatly from the test stimuli (e.g., familiarized with upside down caricatures of faces and tested with right-side up photographs of faces). Besides that, there have been a handful of other WM studies with infants that, while not explicitly designed to investigate $\mathrm{PI}$, have invoked $\mathrm{PI}$ to explain their results (Choi et al., 2018; Oakes \& Kovack-Lesh, 2013). This significant gap in the developmental literature most likely stems from a challenge in tailoring classic WM tasks to children with weak or no expressive language skills. However, further study of $\mathrm{PI}$ in infants and young children would be possible if based on paradigms used successfully in the study of visual WM.

\section{The network underlying PI resolution is immature in children}

Neuroimaging studies of WM development began in the mid-90's (Bunge et al., 2002; Casey et al., 1995; Klingberg et al., 2002; Nelson et al., 2000). These fMRI studies were complemented by EEG and recently by functional near-infrared imaging (fNIRS) studies (Bell \& Wolfe, 2007; Perlman et al., 2016). These studies have shown that activity in the fronto-parietal system during WM tasks emerges early (Fitch et al., 20I6), and the same areas that show WM load-dependent activity (intraparietal, superior frontal and dorsolateral frontal regions) become gradually active in children as well (Luna et al., 20I0; Yaple \& Arsalidou, 2018).

While there has been extensive research on the WM network in general, very little work has focused on disentangling PI effects in development. No studies thus far have used a recent probes task, nor analyzed performance in the $\mathrm{N}$-back task with repeated versus unique stimuli to measure brain activity during PI resolution in children. Some of the studies on WM processes have invoked overlapping systems. For example, Crone and colleagues (Crone et al., 2006) studied the neural mechanisms underlying maintenance and manipulation of information in a WM task using fMRI in 8-12-year-olds, 13-17-year-olds, and adults. Although this study did not investigate PI directly, the task required a manipulation of information that necessitated the inhibition of recently encoded information. On a typical trial, participants were presented with three pictures of familiar objects followed by a direction either "forward" or "backward." Next, participants were presented with a picture of one of the previously presented objects and were asked whether this item had been the first, second, or third item presented. "Forward" direction did not require the manipulation of information, in contrast with the "backward" or manipulation trials which required the participant to reorder the items in their mind and overwrite the recently encoded, salient forward order. Younger children's (ages 8-12) performance was well below older children's (ages 13-17) or young adults'. Crucially, the imaging results revealed that older children and adults recruited the right dIPFC and bilateral superior gyrus (in the posterior parietal cortex) during the delay period, whereas the 8-12year-olds failed to recruit these areas. 
If we turn our attention specifically to the left IFG, the area that has consistently been invoked in interference resolution in adults, there are a handful of studies that have found protracted development. For example, an fMRI study found weaker top-down modulatory influences from the inferior frontal area to parietal and temporal regions in 9-12-year-olds (Bitan et al., 2006), however this was not in the context of a WM task. In a verbal WM task, Vogan and colleagues found lower activation of the left IFG in 9-15-year-old children (Vogan et al., 2016) compared to adults, and activity in this region was related to performance (along with the left middle frontal gyrus and bilaterally in the superior parietal gyrus).

Aside from studies that can only provide indirect evidence for the mechanisms of interference resolution in children, to our knowledge, there has been only one study that directly investigated the neural substrates of PI in children (Polspoel et al., 2019). The same research group that identified PI as the main factor behind arithmetical problem-solving in children (see Section 5 above) conducted an fMRI study on interference and load (problem size) in adults, and found that - just as in studies of WM using the recent probes task - the left IFG showed differential activation related to interference (De Visscher et al., 2018). In the Polspoel et al. (2019) study, they tested 9-10-year-olds in the same paradigm. They found clear behavioral effects of both interference and load on children's performance. They also found a strong effect of load on the activity of the posterior parietal cortex, frontal cortex (precentral gyrus), and the occipital cortex (fusiform gyrus). However, for the interference effect, the results of this study were unfortunately inconclusive, as no significant activation differences between low- and high-interfering problems were found in the full factorial model, or in the whole-brain contrasts when correcting for multiple comparisons. The authors provided some methodological reasons for this surprising result.

Overall, the lack of studies on the neural mechanisms of PI resolution in children is a significant gap in the literature, and future research (using fMRI, EEG, and fNIRS) should aim at characterizing the development of these mechanisms.

\section{How PI affects estimates of infants' working memory capacity}

Most developmental research has measured WM capacity by presenting participants with consecutive trials containing highly similar, if not identical, stimuli. Unwittingly, as we have seen from this review, this creates an ideal context for PI. Ironically, this repeated-stimuli-over-trials design has been used to ensure that the child (or primate) was, in fact, using WM to solve the task (Mishkin, 1978). In the primate neurophysiological literature, this became known as trial-unique versus trial-non-unique presentation (Stern et al., 200I). The logic of this design was that when a series of trials contains repeated stimuli, the participant is required to update their mental representations on every trial, therefore ensuring that they are exploiting WM, and not 'long-term' recognition memory alone. This design directly entangles PI with estimates of WM capacity. Since in these paradigms, average performance over all trials is used to estimate WM capacity, it is very likely that we have been (perhaps considerably) underestimating children's WM capacity.

As an exercise to gain insight, we conducted a meta-analysis of trial-by-trial data from infant studies that attempted to characterize visual WM capacity using a paradigm with multiple trials containing repeated stimuli. We adopted the same method as Kail (2002) to test whether estimates of infants' memory performance dropped across trials. (Note: just as in Kail (2002), the analyzed studies were not specifically designed to test effects of PI.) We followed the standard guidelines for meta-analyses (Harrer et al., 202I). Papers were found by conducting a search on PubMed using the keywords "visual working memory" and "infant" in October 2020. The search yielded a total of 24 potentially relevant papers.

These 24 papers used one of three paradigms: change detection, violation of expectation, or Delayed Match Retrieval. We ultimately decided to only analyze results from studies using one of these paradigms: violationof expectation. We did not include change detection studies for two reasons. (I) This paradigm measures memory processes at a very short timescale (hundreds of milliseconds versus several seconds in other WM paradigms), and (2) in these studies, the repetition of items from trial to trial was randomized for each participant, and there was no way of extracting data to contrast performance in repetition versus no-repetition trial pairs. We decided not to include Delayed Match Retrieval studies in the meta-analysis either, because (I) the task demands were different from that of the violation-of-expectation task (rule learning plus anticipatory looking versus passive detection of novelty, see Kaldy et al., 2016), and (2) the dependent variables were also different (2-alternative choice versus looking time). 19 of the 24 studies were eliminated because the authors did not use a violation-ofexpectation paradigm or did not present infants with at least three experimental trials (necessary to see the trial- 
by-trial buildup of interference). If all other criteria were met but the authors did not report trial-by-trial data, the authors were contacted for their raw data.

The final data set included 5 studies (15 experiments, 40I infants), all of which used a violation-ofexpectation paradigm (see Table 2). While this was not one of our specified criteria, all of these 5 studies employed a between-subjects design. The infants in this final set of studies were between 6 and 12 months of age (Mean age $=7.5+/-1.9$ months). Unfortunately, we could not find any violation-of-expectation studies measuring WM capacity in toddlers ( 12 months - 3-year-olds) with stimuli repeated across multiple trials. Ultimately, our search resulted in a small set of methodologically highly homogeneous studies. It should be noted that these 15 experiments were conducted by three researchers working in the same laboratory, which limits the generalizability of the findings. Future studies designed specifically to measure PI effects in infants are needed.

\begin{tabular}{|l|c|c|c|c|}
\hline \multicolumn{1}{|c|}{ Authors and year } & $\begin{array}{c}\text { Expt. } \\
\text { number }\end{array}$ & $\begin{array}{c}\text { age } \\
\text { (months) }\end{array}$ & $\begin{array}{c}\mathbf{N} \text { (expected } \\
\text { condition) }\end{array}$ & $\begin{array}{c}\mathbf{N} \text { (unexpected } \\
\text { condition) }\end{array}$ \\
\hline Kaldy \& Leslie (2003) & 1 & 8.9 & 20 & 12 \\
\hline Kaldy \& Leslie (2003) & 1 & 8.9 & 20 & 12 \\
\hline Kaldy \& Leslie (2003) & 1 & 8.9 & 20 & 20 \\
\hline Kaldy \& Leslie (2003) & 2 & 9.0 & 12 & 15 \\
\hline Kaldy \& Leslie (2003) & 2 & 9.0 & 12 & 12 \\
\hline Kibbe \& Leslie (2011) & 1 & 5.8 & 12 & 12 \\
\hline Kibbe \& Leslie (2011) & 1 & 5.8 & 12 & 12 \\
\hline Kibbe \& Leslie (2013) & 2 & 8.8 & 12 & 12 \\
\hline Kibbe \& Leslie (2013) & 4 & 11.6 & 12 & 12 \\
\hline Kibbe \& Leslie (2019) & 1 & 5.9 & 12 & 12 \\
\hline Kibbe \& Leslie (2019) & 3 & 5.9 & 12 & 15 \\
\hline Kibbe \& Leslie (2019) & 3 & 5.9 & 12 & 15 \\
\hline Kibbe \& Leslie (2016) & 1 & 6.0 & 12 & 12 \\
\hline Kibbe \& Leslie (2016) & 1 & 5.9 & 12 & 12 \\
\hline Kibbe \& Leslie (2016) & 2 & 5.9 & 12 & 12 \\
\hline
\end{tabular}

Table 2. Studies that were included in our meta-analysis. These studies investigated infants' visual WM using repeated items over multiple trials in the violation-of-expectation paradigm.

In violation-of-expectation tasks, infants are presented with a sequence of events (for example, a triangle being hidden behind a screen on the left and a disk behind a screen on the right, e.g. Kaldy \& Leslie, 2003). After a short delay, the screens are removed to reveal either an unexpected outcome (objects in the reversed position, a violation of spatiotemporal continuity), or an expected outcome (triangle on the left, disk on the right). If infants remember 'what was where', they will look longer at the unexpected outcome.

In order to create a measure that can be used as a proxy for WM performance, we subtracted the mean looking times of the expected outcome group from the unexpected outcome group to calculate baseline-corrected mean looking times for the first three trials. Similarly to Kail (2002), we analyzed the difference in the average looking times between Trial I and Trial 2 and Trial I and Trial 3 where importantly, looking times were corrected with baseline looking times in the expected condition. We calculated Hedges $g$ to quantify the effect size of these differences in each of the studies. We then ran separate random effect models for each of the two comparisons. The overall effect of the Trial I - Trial 2 difference was not significant $(g=-0.06,95 \% \mathrm{Cl}:-0.34-0.2 \mathrm{I}, p=$ n.s.). However, we found a significant overall effect, $g=0.37$ (95\% Cl: $0.28-0.57, p=0.0002)$ of the Trial I - Trial 3 difference, with the heterogeneity among studies being non-significant $(\mathrm{Q}(14)=12.9, p=$ n.s.) (See Figure 5). That is, we found a significant drop in looking times to the baseline-corrected unexpected outcome from Trial I to Trial 3 (i.e., an interaction effect between Condition and Trials). Our interpretation of this finding is that PI affects 6-I2-month-old infants' WM performance, and could at least partially explain their low capacity previously measured in this paradigm. Looking forward, a systematic comparison of WM tests with a series of trial-unique versus trial-non-unique stimuli could further characterize the PI effect in infants. 


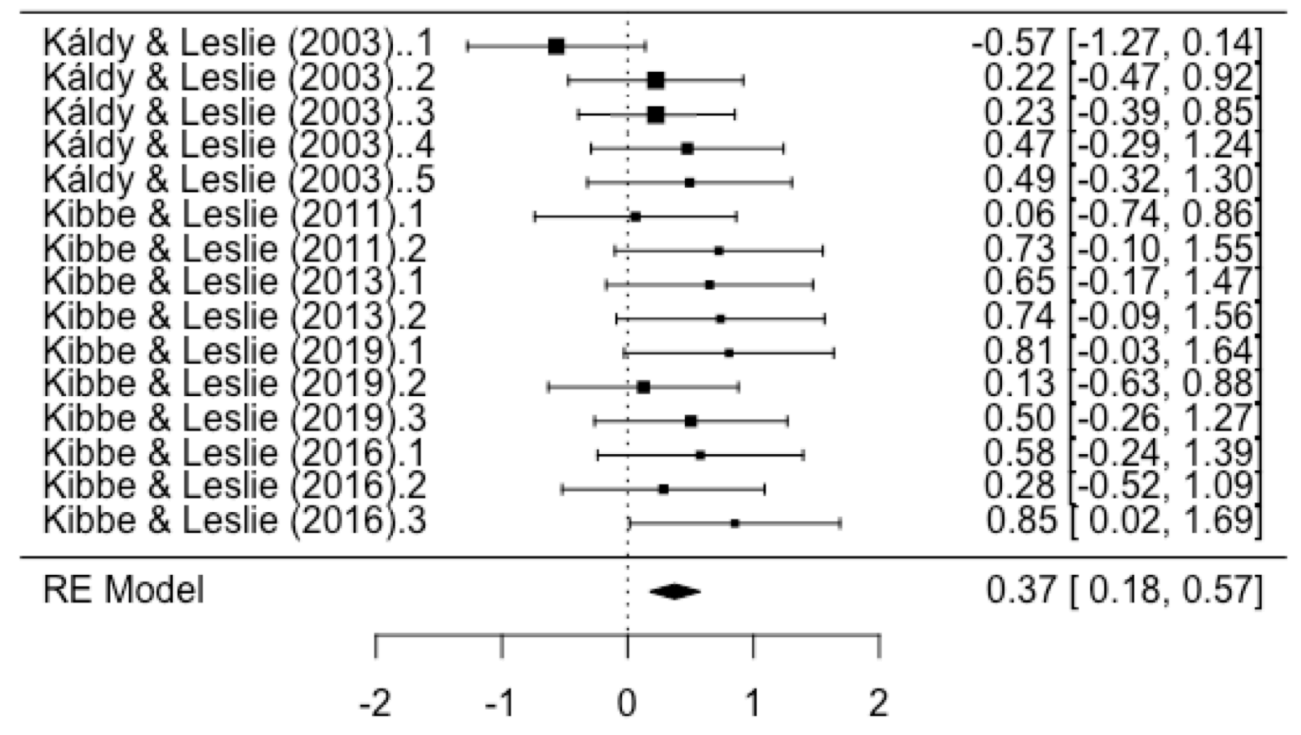

Standardized Mean Difference

Figure 5. Forest plot depicting effect sizes (Hedges $g$ ) in our meta-analysis ( 5 articles, 15 studies, 401 infant participants) testing the difference between (baseline-corrected) Trial I and Trial 3 performance. Overall effect size is $0.37, p=$ 0.0002

Of course, this re-analysis of previously published data does not allow us to claim that $\mathrm{Pl}$ is the only reason for the decline in infants' performance across trials. It is possible that other factors may contribute to the drop in corrected looking times to the unexpected outcome we observed, such as a potential habituation to the surprising outcome. To evaluate this particular alternative, we surveyed all of the classic, non-WM based (i.e., physical impossibility) violation-of-expectation studies by Baillargeon and her colleagues that used more than one test trial, such as the drawbridge study (Baillargeon, 1987). If habituation to physical impossibility is at the heart of the reduction in looking times to the unexpected outcome in the WM studies of our meta-analysis, then it should be at play in these non-WM studies as well. However, here we found that in 31 out of their 32 experiments there was no significant interaction between the factors of Trials and Condition ('Control' experiments where a Condition effect was not observed were omitted from this analysis). Thus, it does not seem that a selective habituation to unexpected outcomes can explain the interaction effect we found in our meta-analysis.

\section{Summary and future directions}

In this review and targeted meta-analysis, we tied together several threads in the literature to support the argument that developmental increases in working memory capacity are driven by increases in the ability to cope with proactive interference, and further, the implication that we have likely been underestimating young children's WM capacity.

We first reviewed the literature providing evidence that $\mathrm{PI}$ affects WM capacity in adults. We then outlined the literature establishing that the resolution of PI in adults is mediated by a network including areas of the frontal cortex, the posterior parietal cortex, and the MTL. Next, we showed that WM capacity is more limited in children and that children are, in fact, sensitive to the effects of PI (see Table 2). Lastly, we presented (so far, mainly indirect) evidence that the cortical network underlying PI resolution is immature in children.

To date, there have been no studies directly measuring the effect of PI or underlying cognitive mechanisms in children under 4 years of age. In order to help determine whether PI may be a limiting factor on WM in early development, we conducted a targeted meta-analysis of a highly homogeneous set of infant studies. Most developmental research measures WM capacity by presenting participants with consecutive trials containing highly similar, if not identical, stimuli. Unwittingly, this has created an ideal context for PI. Using a technique based on a similar meta-analysis of studies with older children (Kail, 2002), trial-by-trial trends showed a pattern consistent with the accumulation of PI. This result suggests that we may be underestimating WM capacity in early childhood, and we argue that research explicitly measuring how the ability to cope with PI modulates WM capacity within, and across, age groups is needed. 
Finally, while a sophisticated description of the brain networks underlying interference resolution in adults has emerged, very little work has focused on disentangling the neural mechanisms of PI resolution in development. This is a significant gap in the literature, and we suggest that future EEG, fMRI and fNIRS studies should directly investigate the development of the network underlying interference resolution in WM across childhood. 


\section{REFERENCES}

Anderson, M. C. (2003). Rethinking interference theory: Executive control and the mechanisms of forgetting. Journal of Memory and Language, 49(4), 4I5-445.

Anderson, M. C., \& Green, C. (200I). Suppressing unwanted memories by executive control. Nature, 4I 0(6826), 366-369.

Anderson, M. C., \& Hulbert, J. C. (202I). Active Forgetting: Adaptation of Memory by Prefrontal Control. Annual Review of Psychology, 72, I-36.

Anderson, M. C., \& Neely, J. H. (1996). Chapter 8 - Interference and Inhibition in Memory Retrieval. In E. L. Bjork \& R. A. Bjork (Eds.), Memory (pp. 237-3।3). Academic Press.

Anderson, M. C., Ochsner, K. N., Kuhl, B., Cooper, J., Robertson, E., Gabrieli, S. W., Glover, G. H., \& Gabrieli, J. D. E. (2004). Neural systems underlying the suppression of unwanted memories. Science, 303(5655), 232235.

Aydmune, Y., Introzzi, I., Zamora, E., \& Stelzer, F. (2020). Inhibitory Processes and Fluid Intelligence: A Performance at Early Years of Schooling. International Journal of Psychological Research, I3(I), 29-39.

Baddeley, A. D., \& Hitch, G. (1974). Working Memory. In G. H. Bower (Ed.), Psychology of Learning and Motivation (Vol. 8, pp. 47-89). Academic Press.

Badre, D., \& Wagner, A. D. (2005). Frontal lobe mechanisms that resolve proactive interference. Cerebral Cortex, I5(I2), 2003-20I2.

Baillargeon, R. (1987). Object permanence in 31/2-and 41/2-month-old infants. Developmental Psychology, 23(5), 655-664.

Barrouillet, P., Bernardin, S., \& Camos, V. (2004). Time constraints and resource sharing in adults' working memory spans. Journal of Experimental Psychology: General, I33(I), 83-100.

Barrouillet, P., Bernardin, S., Portrat, S., Vergauwe, E., \& Camos, V. (2007). Time and cognitive load in working memory. Journal of Experimental Psychology: Learning, Memory, and Cognition, 33(3), 570-585.

Bell, M. A., \& Wolfe, C. D. (2007). Changes in brain functioning from infancy to early childhood: evidence from EEG power and coherence working memory tasks. Developmental Neuropsychology, 3I(I), 2I-38.

Bitan, T., Burman, D. D., Lu, D., Cone, N. E., Gitelman, D. R., Mesulam, M.-M., \& Booth, J. R. (2006). Weaker top-down modulation from the left inferior frontal gyrus in children. Neurolmage, 33(3), 99I-998.

Bjorklund, D. F., Smith, S. C., \& Ornstein, P. A. (1982). Young children's release from proactive interference: The effects of category typicality. Bulletin of the Psychonomic Society, 20(4), 2II-2I3.

Bjork, R. A., LaBerge, D., \& Legrand, R. (1968). The modification of short-term memory through instructions to forget. Psychonomic Science, I0(2), 55-56.

Braver, T. S. (2012). The variable nature of cognitive control: a dual mechanisms framework. Trends in Cognitive Sciences, I6(2), 106-1 I3.

Braver, T. S., Gray, J. R., \& Burgess, G. C. (2007). Explaining the many varieties of working memory variation: Dual mechanisms of cognitive control. In A. R. A. Conway, C. Jarrold, M. J. Kane (Eds.) \& A. Miyake \& J. N. Towse (Ed.), Variation in working memory (pp. 76-106). Oxford University Press.

Brown, G. D. A., Neath, I., \& Chater, N. (2007). A temporal ratio model of memory. Psychological Review, I / 4(3), 539-576.

Bunge, S. A., Dudukovic, N. M., Thomason, M. E., Vaidya, C. J., \& Gabrieli, J. D. E. (2002). Immature frontal lobe contributions to cognitive control in children: evidence from fMRI. Neuron, 33(2), 30 I-3 I I.

Bunge, S. A., Ochsner, K. N., Desmond, J. E., Glover, G. H., \& Gabrieli, J. D. (200I). Prefrontal regions involved in keeping information in and out of mind. Brain, I24(Pt I0), 2074-2086.

Bunting, M. (2006). Proactive interference and item similarity in working memory. Journal of Experimental Psychology: Learning, Memory, and Cognition, 32(2), 183-196.

Burnett Heyes, S., Zokaei, N., van der Staaij, I., Bays, P. M., \& Husain, M. (20I2). Development of visual working memory precision in childhood. Developmental Science, 15(4), 528-539.

Campbell, J. I. (1997). On the relation between skilled performance of simple division and multiplication. Journal of Experimental Psychology: Learning, Memory, and Cognition, 23(5), I I 40-I I 59.

Cann, L. F., Liberty, C., Shafto, M., \& Ornstein, P. A. (1973). Release from proactive interference with young children. Developmental Psychology, 8(3), 396.

Carriedo, N., Corral, A., Montoro, P. R., Herrero, L., \& Rucián, M. (2016). Development of the updating executive function: From 7-year-olds to young adults. Developmental Psychology, 52(4), 666-678. 
Casey, B. J., Cohen, J. D., Jezzard, P., Turner, R., Noll, D. C., Trainor, R. J., Giedd, J., Kaysen, D., Hertz-Pannier, L., \& Rapoport, J. L. (1995). Activation of prefrontal cortex in children during a nonspatial working memory task with functional MRI. Neurolmage, 2(3), $221-229$.

Chatham, C. H., Frank, M. J., \& Munakata, Y. (2009). Pupillometric and behavioral markers of a developmental shift in the temporal dynamics of cognitive control. Proceedings of the National Academy of Sciences of the United States of America, 106(14), 5529-5533.

Chevalier, N., Martis, S. B., Curran, T., \& Munakata, Y. (2015). Metacognitive processes in executive control development: the case of reactive and proactive control. Journal of Cognitive Neuroscience, 27(6), I I $25-1$ I 36.

Chiappe, P., Hasher, L., \& Siegel, L. S. (2000). Working memory, inhibitory control, and reading disability. Memory \& Cognition, 28(I), 8-17.

Choi, K., Kirkorian, H. L., \& Pempek, T. A. (20I8). Understanding the Transfer Deficit: Contextual Mismatch, Proactive Interference, and Working Memory Affect Toddlers' Video-Based Transfer. Child Development, 89(4), | $378-1393$.

Cowan, N. (200I). The magical number 4 in short-term memory: a reconsideration of mental storage capacity. The Behavioral and Brain Sciences, 24(I), 87-I I4; discussion II4-I85.

Cowan, N. (2016). Working Memory Maturation: Can We Get at the Essence of Cognitive Growth? Perspectives on Psychological Science, I I (2), 239-264.

Cowan, N., Elliott, E. M., Saults, J., Morey, C. C., Mattox, S., Hismjatullina, A., \& Conway, A. R. A. (2005). On the capacity of attention: its estimation and its role in working memory and cognitive aptitudes. Cognitive Psychology, 5I(I), 42-100.

Crone, E. A., Wendelken, C., Donohue, S., van Leijenhorst, L., \& Bunge, S. A. (2006). Neurocognitive development of the ability to manipulate information in working memory. Proceedings of the National Academy of Sciences of the United States of America, 103(24), 9315-9320.

Curtis, C. E., \& D'Esposito, M. (2003). Persistent activity in the prefrontal cortex during working memory. Trends in Cognitive Sciences, 7(9), 4I5-423.

Cyr, M., Nee, D. E., Nelson, E., Senger, T., Jonides, J., \& Malapani, C. (20I7). Effects of proactive interference on non-verbal working memory. Cognitive Processing, I8(I), I-I2.

Davidson, M. C., Amso, D., Anderson, L. C., \& Diamond, A. (2006). Development of cognitive control and executive functions from 4 to 13 years: Evidence from manipulations of memory, inhibition, and task switching. Neuropsychologia, 44(I I), 2037-2078.

Dempster, F. N. (198I). Memory span: Sources of individual and developmental differences. Psychological Bulletin, 89(I), 63-100.

De Visscher, A., \& Noël, M.-P. (20I4). The detrimental effect of interference in multiplication facts storing: typical development and individual differences. Journal of Experimental Psychology. General, 143(6), 23802400.

De Visscher, A., Szmalec, A., Van Der Linden, L., \& Noël, M.-P. (20I5). Serial-order learning impairment and hypersensitivity-to-interference in dyscalculia. Cognition, 144, 38-48.

De Visscher, A., Vogel, S. E., Reishofer, G., Hassler, E., Koschutnig, K., De Smedt, B., \& Grabner, R. H. (20I8). Interference and problem size effect in multiplication fact solving: Individual differences in brain activations and arithmetic performance. Neurolmage, 172, 718-727.

Duncan, J., \& Owen, A. M. (2000). Common regions of the human frontal lobe recruited by diverse cognitive demands. Trends in Neurosciences, 23(I0), 475-483.

Durston, S., Thomas, K., Worden, M., Silbersweig, D., Stern, E., Yang, Y., \& Casey, B. J. (200I). The effect of context on inhibition in normal development: An fMRI study. Neurolmage, 13(6), 3I2.

Elliott, E. M., Morey, C. C., AuBuchon, A. M., Cowan, N., Jarrold, C., Adams, E. J., Attwood, M., Bayram, B., Beeler-Duden, S., Blakstvedt, T. Y., Büttner, G., Castelain, T., Cave, S., Crepaldi, D., Fredriksen, E., Glass, B. A., Graves, A. J., Guitard, D., Hoehl, S., ... Voracek, M. (202I). Multilab Direct Replication of Flavell, Beach, and Chinsky (1966): Spontaneous Verbal Rehearsal in a Memory Task as a Function of Age. Advances in Methods and Practices in Psychological Science, 4(2), 25I524592I I 018187.

Endress, A. D., \& Potter, M. C. (2014). Large capacity temporary visual memory. Journal of Experimental Psychology: General, I 43(2), 548-565.

Esrov, L. V., Hall, J. W., \& LaFaver, D. K. (1974). Preschoolers' conceptual and acoustic encoding as evidenced by release from PI. Bulletin of the Psychonomic Society, 4(2), 89-90. 
Feredoes, E., Tononi, G., \& Postle, B. R. (2006). Direct evidence for a prefrontal contribution to the control of proactive interference in verbal working memory. Proceedings of the National Academy of Sciences of the United States of America, 103(5I), 19530-19534.

Fitch, A., Smith, H., Guillory, S. B., \& Kaldy, Z. (2016). Off to a Good Start: The Early Development of the Neural Substrates Underlying Visual Working Memory. Frontiers in Systems Neuroscience, 10, 68.

Gathercole, S. E., Pickering, S. J., Ambridge, B., \& Wearing, H. (2004). The structure of working memory from 4 to 15 years of age. Developmental Psychology, 40(2), 177.

Guillory, S. B., Gliga, T., \& Kaldy, Z. (2018). Quantifying attentional effects on the fidelity and biases of visual working memory in young children. Journal of Experimental Child Psychology, 167, 146-161.

Halford, G. S., Maybery, M. T., \& Bain, J. D. (1988). Set-size effects in primary memory: an age-related capacity limitation? Memory \& Cognition, I6(5), 480-487.

Harrer, M., Taylor \& Francis Group, Cuijpers, P., Furukawa, T. A., \& Ebert, D. D. (202I). Doing Meta-Analysis with R: A Hands-On Guide. Taylor \& Francis Group.

Hartshorne, J. K. (2008). Visual working memory capacity and proactive interference. PloS One, 3(7), e27l6.

Irlbacher, K., Kraft, A., Kehrer, S., \& Brandt, S. A. (20I4). Mechanisms and neuronal networks involved in reactive and proactive cognitive control of interference in working memory. Neuroscience and Biobehavioral Reviews, 46(I), 58-70.

Jonides, J., \& Nee, D. E. (2006). Brain mechanisms of proactive interference in working memory. Neuroscience, 139(I), 181-193.

Jonides, J., Schumacher, E. H., Smith, E. E., Koeppe, R. A., Awh, E., Reuter-Lorenz, P. A., Marshuetz, C., \& Willis, C. R. (1998). The role of parietal cortex in verbal working memory. The Journal of Neuroscience, I8(I3), 5026-5034.

Kail, R. (2002). Developmental change in proactive interference. Child Development, 73(6), I703-I7|4.

Kaldy, Z., Guillory, S. B., \& Blaser, E. (2016). Delayed Match Retrieval: A novel anticipation-based visual working memory paradigm. Developmental Science, 19(6), 892-900.

Kaldy, Z., \& Leslie, A. M. (2003). Identification of objects in 9-month-old infants: integrating "what" and "where" information. Developmental Science, 6(3), 360-373.

Kaldy, Z., \& Leslie, A. M. (2005). A memory span of one? Object identification in 6.5-month-old infants. Cognition, 97(2), I53-177.

Kane, M. J., \& Engle, R. W. (2000). Working-memory capacity, proactive interference, and divided attention: limits on long-term memory retrieval. Journal of Experimental Psychology: Learning, Memory, and Cognition, 26(2), 336-358.

Keppel, G., \& Underwood, B. J. (1962). Proactive inhibition in short-term retention of single items. Journal of Verbal Learning and Verbal Behavior, I(3), I53-16I.

Kibbe, M. M., \& Leslie, A. M. (20I I). What do infants remember when they forget? Location and identity in 6month-olds' memory for objects. Psychological Science, 22(I2), I500-1505.

Kibbe, M. M., \& Leslie, A. M. (2013). What's the object of object working memory in infancy? Unraveling "what"and "how many." Cognitive Psychology, 66(4), 380-404.

Kibbe, M. M., \& Leslie, A. M. (2016). The ring that does not bind: Topological class in infants' working memory for objects. Cognitive Development, 38, I-9.

Kibbe, M. M., \& Leslie, A. M. (2019). Conceptually Rich, Perceptually Sparse: Object Representations in 6Month-Old Infants' Working Memory. Psychological Science, 30(3), 362-375.

Kincaid, J. P., \& Wickens, D. D. (1970). Temporal gradient of release from proactive inhibition. Journal of Experimental Psychology, 86(2), 3I3-316.

Kliegl, O., \& Bäuml, K.-H. T. (202I). Buildup and release from proactive interference - Cognitive and neural mechanisms. Neuroscience \& Biobehavioral Reviews, 120, 264-278.

Klingberg, T., Forssberg, H., \& Westerberg, H. (2002). Increased brain activity in frontal and parietal cortex underlies the development of visuospatial working memory capacity during childhood. Journal of Cognitive Neuroscience, I4(I), I-I0.

Levy, B. J., \& Anderson, M. C. (2002). Inhibitory processes and the control of memory retrieval. Trends in Cognitive Sciences, 6(7), 299-305.

Lin, P.-H., \& Luck, S. J. (20I2). Proactive interference does not meaningfully distort visual working memory capacity estimates in the canonical change detection task. Frontiers in Psychology, 3, 42. 
Loess, H. W. (1967). Short-Term Memory and Intertrial Interval. Journal of Verbal Learning and Verbal Behavior, 6(4), 455-460.

Loosli, S. V., Rahm, B., Unterrainer, J. M., Weiller, C., \& Kaller, C. P. (20I4). Developmental change in proactive interference across the life span: Evidence from two working memory tasks. Developmental Psychology, 50(4), 1060-1072.

Luna, B., Padmanabhan, A., \& O'Hearn, K. (20I0). What has fMRI told us about the Development of Cognitive Control through Adolescence? Brain and Cognition, 72(I), I0I-II3.

Lustig, C., May, C. P., \& Hasher, L. (200I). Working memory span and the role of proactive interference. Journal of Experimental Psychology: General, 130(2), 199-207.

MacDonald, A. W., 3rd, Cohen, J. D., Stenger, V. A., \& Carter, C. S. (2000). Dissociating the role of the dorsolateral prefrontal and anterior cingulate cortex in cognitive control. Science, 288(5472), 1835-1838.

Makovski, T. (2016). Does proactive interference play a significant role in visual working memory tasks? Journal of Experimental Psychology: Learning, Memory, and Cognition, 42(10), 1664-1672.

Makovski, T., \& Jiang, Y. V. (2008). Proactive interference from items previously stored in visual working memory. Memory \& Cognition, 36(I), 43-52.

Mecklinger, A., Weber, K., Gunter, T. C., \& Engle, R. W. (2003). Dissociable brain mechanisms for inhibitory control: effects of interference content and working memory capacity. Brain Research. Cognitive Brain Research, 18(1), 26-38.

Monsell, S. (1978). Recency, immediate recognition memory, and reaction time. Cognitive Psychology, 10(4), 465$50 \mathrm{I}$.

Nee, D. E., Jonides, J., \& Berman, M. G. (2007). Neural mechanisms of proactive interference-resolution. Neurolmage, 38(4), 740-75I.

Nelson, C. A., Monk, C. S., Lin, J., Carver, L. J., Thomas, K. M., \& Truwit, C. L. (2000). Functional neuroanatomy of spatial working memory in children. Developmental Psychology, 36(I), I09-1I6.

Oakes, L. M., \& Kovack-Lesh, K. A. (2013). Infants' Visual Recognition Memory for a Series of Categorically Related Items. Journal of Cognition and Development, 4(I), 63-86.

Oberauer, K., Farrell, S., Jarrold, C., \& Lewandowsky, S. (2016). What limits working memory capacity? Psychological Bulletin, I42(7), 758-799.

Oberauer, K., Lewandowsky, S., Farrell, S., Jarrold, C., \& Greaves, M. (20I2). Modeling working memory: An interference model of complex span. Psychonomic Bulletin \& Review, 19(5), 779-819.

Öztekin, I., \& Badre, D. (20I I). Distributed Patterns of Brain Activity that Lead to Forgetting. Frontiers in Human Neuroscience, $5,86$.

Öztekin, I., Curtis, C. E., \& McElree, B. (2009). The medial temporal lobe and the left inferior prefrontal cortex jointly support interference resolution in verbal working memory. Journal of Cognitive Neuroscience, 2 I ( I0), 1967-1979.

Pelphrey, K. A., Reznick, J. S., Davis Goldman, B., Sasson, N., Morrow, J., Donahoe, A., \& Hodgson, K. (2004). Development of visuospatial short-term memory in the second half of the Ist year. Developmental Psychology, 40(5), 836-85I.

Perlman, S. B., Huppert, T. J., \& Luna, B. (2016). Functional Near-Infrared Spectroscopy Evidence for Development of Prefrontal Engagement in Working Memory in Early Through Middle Childhood. Cerebral Cortex, 26(6), 2790-2799.

Polspoel, B., De Visscher, A., Vandermosten, M., Vogel, S. E., Grabner, R. H., \& De Smedt, B. (2019). The neural substrates of the problem size and interference effect in children's multiplication: An fMRI study. Brain Research, I7/4, I47-157.

Reutener, D. B., \& Fang, J. (1985). Encoding Processes and Release from Proactive Interference in Short-Term Memory of Preschool Children. The Journal of General Psychology, II 2(4), 343-348.

Riggs, K. J., McTaggart, J., Simpson, A., \& Freeman, R. P. J. (2006). Changes in the capacity of visual working memory in 5- to 10-year-olds. Journal of Experimental Child Psychology, 95(I), I8-26.

Rosner, S. R. (1972). Primacy in preschoolers' short-term memory: The effects or repeated tests and shift-trials. Journal of Experimental Child Psychology, I3(I), 220-230.

Ross-Sheehy, S., Oakes, L. M., \& Luck, S. J. (2003). The development of visual short-term memory capacity in infants. Child Development, 74(6), I807-I822. 
Shipstead, Z., \& Engle, R. W. (20I3). Interference within the focus of attention: working memory tasks reflect more than temporary maintenance. Journal of Experimental Psychology. Learning, Memory, and Cognition, 39(I), 277-289.

Simmering, V. R. (20I2). The development of visual working memory capacity during early childhood. Journal of Experimental Child Psychology, II I (4), 695-707.

Stern, C. E., Sherman, S. J., Kirchhoff, B. A., \& Hasselmo, M. E. (200I). Medial temporal and prefrontal contributions to working memory tasks with novel and familiar stimuli. Hippocampus, II (4), 337-346.

Towse, J. N., \& Hitch, G. J. (1995). Is there a relationship between task demand and storage space in tests of working memory capacity? The Quarterly Journal of Experimental Psychology: A, Human Experimental Psychology, 48(I), 108-124.

Tyrrell, D. J., Pressman, M., Cunningham, T., Steele, G. M., \& Thaller, K. (I98I). Input and distractor modality effects upon the release from proactive interference in children. The Journal of Genetic Psychology, I39(2d Half), 205-220.

Tyrrell, D. J., Snowman, L. G., Beier, J. A., \& Blanck, C. M. (1990). Proactive interference in infant recognition memory. Bulletin of the Psychonomic Society, 28(3), 188-190.

Underwood, B. J. (1957). Interference and forgetting. Psychological Review, 64(I), 49-60.

Vogan, V. M., Morgan, B. R., Powell, T. L., Smith, M. L., \& Taylor, M. J. (2016). The neurodevelopmental differences of increasing verbal working memory demand in children and adults. Developmental Cognitive Neuroscience, 17, 19-27.

Weiss, A. R., Nadji, R., \& Bachevalier, J. (2015). Neonatal Perirhinal Lesions in Rhesus Macaques Alter Performance on Working Memory Tasks with High Proactive Interference. Frontiers in Systems Neuroscience, 9, 179.

Wickens, D. D., Born, D. G., \& Allen, C. K. (1963). Proactive inhibition and item similarity in short-term memory. Journal of Verbal Learning and Verbal Behavior, 2(5), 440-445.

Wolfe, C. D., \& Bell, M. A. (2004). Working memory and inhibitory control in early childhood: Contributions from physiology, temperament, and language. Developmental Psychobiology, 44(I), 68-83.

Yaple, Z., \& Arsalidou, M. (2018). N-back working memory task: Meta-analysis of normative fMRI studies with children. Child Development, 89(6), 2010-2022. 